\title{
Periferia: um lugar para a identidade no discurso de jornalistas
}

Cláudia Nonato

Universidade de São Paulo, São Paulo, Brasil

\section{Fernando Felício Pachi Filho}

Faculdade de Tecnologia Termomecânica, São Bernardo do Campo, São Paulo, Brasil Universidade Paulista, São Paulo, São Paulo, Brasil

Camila Acosta Camargo

Universidade de São Paulo, São Paulo, Brasil FIAM-FAAM Centro Universitário, São Paulo, São Paulo, Brasil

\section{Resumo}

Periferia em movimento, Nós, mulheres da Periferia e Vozes são exemplos de iniciativas jornalísticas que delimitam seu campo de atuação em áreas da cidade de São Paulo denominadas de "periferias". O objetivo deste artigo é compreender o processo de discursos instaurado por estes arranjos econômicos alternativos às corporações de mídia e manifesto em entrevistas realizadas com representantes dessas iniciativas. A análise, que segue princípios teórico-metodológicos da Análise de Discurso materialista, indica que a constituição de uma identidade de jornalista da periferia é determinante para sua formulação discursiva e para legitimação de um discurso distinto em relação à mídia hegemônica.

\section{Palavras-chave:}

Jornalismo. Periferia. Análise de Discurso.

\section{Introdução}

Periferia em Movimento, Nós, Mulheres da Periferia e Vozes são arranjos econômicos alternativos de comunicação (NONATO; PACHI FILHO; FIGARO, 2018) que nascem, entre 2012 e 2014, com propósitos semelhantes, a saber: produzir um jornalismo alternativo ao da grande mídia, que ao abordar a periferia acentua temáticas assistencialistas e a violência do lugar, alimentando estereótipos sobre essas áreas nas grandes cidades. As periferias possuem uma parcela numerosa da população, e historicamente sempre influenciaram tendências, movimentos culturais e comportamentos da classe dominante, chamada também, em termos geográficos, de "centro". Para esses grupos, no entanto, o centro não é a classe dominante, ou seja, são as periferias (no plural, porque são múltiplas) que estão no centro, demarcando o próprio território como símbolo de resistência e luta cotidianas. 
Diante disso, este artigo apresenta, a partir de um recorte da pesquisa As relações de comunicação e as condições de produção no trabalho de jornalistas em arranjos econômicos alternativos às corporações de mídia ${ }^{1}$ uma análise de entrevistas com representantes desses arranjos com base nos princípios teórico-metodológicos da Análise de Discurso (AD) na tradição materialista (PÊCHEUX, 2014a; ORLANDI, 2015) e da semântica do acontecimento (GUIMARÃEs, 2017). A seguir, apresentamos os procedimentos metodológicos utilizados na coleta e na análise dos dados e uma breve reflexão a respeito das motivações que poderiam ter levado esses profissionais a criarem esses arranjos, a partir do mundo do trabalho e da percepção que trazem a respeito de "periferias". Na sequência, apresentamos aspectos teóricos que constituem o discurso sobre as periferias, com base nos estudos no domínio da Geografia. Por fim, expomos os aspectos discursivos trabalhados na análise e as bases constitutivas do discurso dos entrevistados.

\section{Procedimentos metodológicos}

A realidade em transformação do trabalho jornalístico inclui redes de colaboração diversas, multiplicidade de linguagem e de equipamentos para produção e circulação de informação. Esse contexto nos impõe desafios teórico-metodológicos para a pesquisa. Num primeiro momento, deve-se admitir a instabilidade do campo jornalístico que se altera devido às mudanças profundas e substanciais do sistema produtivo. Optamos, assim, pela realização de uma pesquisa exploratória. Nesse tipo de estudo, busca-se abordar temas ainda pouco estudados e preparar o campo para pesquisas posteriores (SAMPIERI; COLLADO; LUCIO, 2006). Desse modo, buscamos compor o objeto de estudo e a amostra empírica ao longo da pesquisa, na qual foram utilizadas técnicas como entrevistas e grupos de discussão.

Para identificar os informantes e compor a amostra de pesquisa, optamos pela técnica da bola de neve, aplicada a pesquisas de caráter qualitativo e não probabilístico. Esta técnica consiste em buscar um informante em uma população que possa indicar outros informantes até que se obtenha uma saturação das redes de relações entre eles. (HANDCOCK; GILE, 2011). Assim, elegemos como informante a Agência Pública, que havia se dedicado a elaborar o Mapa da Mídia Independente, lançado em 2016. O mapa incluía cerca de 100 arranjos de mídia independente. Os leitores da Agência Pública também haviam acrescentado a ele 
outras indicações. Esse levantamento inicial permitiu também acesso à rede de relações dos informantes contatados. Devido aos recursos disponíveis e ao tempo para a realização da pesquisa, priorizamos os arranjos na Grande São Paulo. Por meio desse critério de seleção, chegamos a 70 arranjos nessa região ${ }^{2}$, entre eles os que se dedicam à comunicação nas periferias.

O corpus de análise deste trabalho foi composto por entrevistas com trabalhadores. Bauer e Gaskell (2007) explicam que a entrevista é um instrumento que possibilita a compreensão das crenças, atitudes, valores e motivações em relação aos comportamentos humanos em contextos específicos. As entrevistas foram realizadas em diferentes locais, em geral com dois entrevistadores, e preferencialmente fora do ambiente de trabalho. Para sua realização, foi elaborado um roteiro de perguntas abertas para conhecer os jornalistas e as formas de organização do seu trabalho no arranjo alternativo. O roteiro buscava também levantar informações sobre a trajetória profissional, categorias como idade, local de nascimento, profissão dos pais, bairro, nível de escolaridade, profissão, tempo no mercado de trabalho e na profissão, história do arranjo, como o trabalho é organizado, o que produzem e quais as rotinas de produção, bem como relacionamento com outros arranjos, perspectivas profissionais e relacionamento com o público.

As entrevistas foram analisadas a partir dos procedimentos teórico-metodológicos da AD materialista. Nesse sentido, do material verbal obtido foram extraídas sequências discursivas que demonstrassem o processo discursivo (ORLANDI, 2015) em curso na fala dos entrevistados. Segundo essa autora, o objetivo da AD não é realizar uma análise exaustiva e completa do objeto de estudo, mas sim identificar o processo discursivo que pode ser analisado e recortado em estados diferentes. O que se pretende é uma exaustividade vertical em relação à temática e aos objetivos estabelecidos. Ao elaborar suas respostas durante a entrevista, o sujeito, tomado pela ilusão de que é fonte de seu dizer, formula seus enunciados a partir de formações discursivas, que se tornam evidentes, produzindo o esquecimento de que o sentido também pode se modificar e ser outro (PÊCHEUX, 2014a; ORLANDI, 2015). O resultado são tomadas de posição nas redes discursivas que manifestam a incidência de

2 No total, foram entrevistados representantes de 29 arranjos alternativos às grandes corporações de mídia. Entre os entrevistados, destacamos para elaboração deste artigo aqueles que tinham sua atuação voltada para a vida nas periferias de São Paulo. Buscamos, assim, apresentar as regularidades discursivas identificadas nas entrevistas com representantes destes arranjos. 
formações discursivas num processo de delimitação de sentidos. Como explica Orlandi (2012), os sentidos no campo discursivo se formam à medida que o sujeito se projeta de sua situação (lugar) no mundo para sua posição no discurso numa articulação complexa entre língua, imaginário e ideologia. Desse modo, há sentidos que se tornam possíveis em detrimento de outros. Nesse processo, as formações discursivas representam o lugar de constituição do sentido e de identificação do sujeito em relação a outros discursos.

O objetivo é compreender como objetos simbólicos, no caso os textos elaborados por sujeitos em entrevistas, produzem sentidos, considerando a não transparência do dizer. Neste aspecto, portanto, a formação do corpus é um gesto de análise, pois a inclusão de materiais para análise é uma decisão sobre características do discurso. Em suma, busca-se compreender o funcionamento do discurso e seus efeitos de sentido.

\section{Histórico e organização}

\section{das três iniciativas}

As crises nos modelos de produção e consumo das mídias tradicionais, associadas à revolução tecnológica, geraram alterações contraditórias no campo jornalístico. Se, por um lado, foram ampliadas as possibilidades de produção com as tecnologias digitais, por outro, o desemprego tornou-se efeito decisivo no mundo do trabalho dos jornalistas. Nesse contexto, impõe-se para os jornalistas a necessidade de buscar formas variadas para se manterem na profissão, processo que redefine as relações de produção e comunicação. Para compreender as alterações ocorridas nas rotinas produtivas, lançamos mão do conceito de arranjo econômico alternativo às grandes corporações de mídia. No âmbito da Economia, os arranjos produtivos locais (NONATO; PACHI FILHO; FIGARO, 2018) são alternativas para o trabalho de grupos de pessoas que exercem atividades autônomas em regiões onde as dinâmicas econômica e social ofereçam condições para seu desempenho. O conceito torna-se produtivo para pensar as configurações no mundo do trabalho dos jornalistas em regiões que se constituem como polos de produção de notícias e serviços jornalísticos, como a Grande São Paulo, onde se concentra nossa pesquisa. Entre esses arranjos jornalísticos, destacam-se aqueles que se dedicam às temáticas relacionadas às periferias.

Em sua trajetória profissional, os jornalistas das três iniciativas trazem em comum a criação dos arranjos durante ou logo após a conclusão da faculdade de jornalismo. São de uma geração que se forma numa época de “desfiguração do trabalho" (ANTUNES, 2018, p. 170), na qual permanecem a informalidade, a precarização e a terceirização. 
O coletivo Periferia em Movimento, criado em 2009, foi estruturado inicialmente como Trabalho de Conclusão de Curso de graduação em jornalismo. Posteriormente, foi adotado como um jornal digital que viabilizasse as ações na periferia, especificamente nas regiões do extremo Sul de São Paulo: Grajaú e Campo Limpo, a partir de documentários, entrevistas, debates e reportagens. Atualmente, é um dos principais articuladores do movimento jornalístico periférico.

O Nós, mulheres da periferia foi criado em 2012 na forma de um blog. Este "coletivo jornalístico", como suas autoras o denominam, é a consequência da repercussão de um artigo publicado na seção de tendências/debates do jornal Folha de S. Paulo (PEDRINA et al., 2012), que se "atentava para a invisibilidade e aos direitos não atendidos de uma parte das mulheres - as que moram em bairros periféricos de grandes metrópoles". O coletivo procura desmistificar a imagem da mulher "preta periférica" e ouvir suas necessidades, dando espaço para suas histórias.

O Vozes (o nome de origem era Vozes da Vila Prudente) foi criado em 2013 e utiliza a comunicação, segundo seu representante, com foco em jornalismo de favelas, com o objetivo de informar e difundir assuntos relacionados às favelas e às periferias, em São Paulo, incentivando o engajamento social, o empreendedorismo, a informação e a cultura. O principal produto do arranjo é um jornal impresso, feito e entregue de forma gratuita por moradores das favelas da Vila Prudente e do Jardim Sinhá, ambas na Zona Leste, e Brasilândia, na Zona Norte de São Paulo. A publicação aborda diversos assuntos das favelas e periferias, tais como cultura, esporte e empreendedorismo. A primeira edição foi lançada em meados de 2015 e desde então o jornal Vozes é entregue de casa em casa, de porta em porta, para milhares de moradores das regiões cobertas.

A escolha dos três coletivos se justifica pelo fato de tratarem de temas e conteúdos voltados para o território, a comunidade, os cidadãos locais, e envolvidos no processo de emancipação dos moradores. Esse tipo de comunicação produzido a partir das periferias aposta no jornalismo feito "de dentro" da comunidade, ou seja, a partir da vivência daqueles moradores, que já estão inseridos naquela realidade. Observa-se que, em alguns casos, os jornalistas atuam também como educomunicadores, ou seja, preparam os jovens para utilizarem adequadamente recursos da comunicação, como instrumentos de expressão da cidadania.

O financiamento e a subsistência revelam-se como os principais limitadores dos arranjos, que utilizaram até aqui recursos após 
aprovação em editais da Prefeitura de São Paulo que visam o fomento de atividades artístico-culturais de grupos e coletivos compostos por jovens e/ou adultos de baixa renda, como o Programa VAI ${ }^{3}$ e o Programa de Fomento à Cultura da Periferia de São Paulo ${ }^{4}$. Como não conseguem alcançar um modelo de negócio que possa abranger sua produção e sustentar os profissionais envolvidos, também se utilizam de financiamento de grandes instituições, como a Fundação Ford, a Fundação Tide Setubal e o Instituto Alana. A contradição capital transnacional - ONGS - movimento sociais (MONTAÑO, 2002) surge remanejada para adequar-se às configurações sociais $d a$ atualidade. Vemos, nesse sentido, a ênfase dos interesses hegemônicos em promover investimentos em atividades do campo da comunicação, entendida como um dos pilares da sociedade contemporânea, de uma forma que os vincula à pauta social ao realizar esta mediação nas áreas mais pobres das cidades.

Ao mesmo tempo que estas iniciativas clamam a emancipação da periferia, elas o fazem utilizando recursos advindos diretamente da classe dominante e, portanto, servindo aos seus interesses. Autores como Montaño (2002) e Yazbek (2018) revelam como os países considerados em desenvolvimento sofrem influência direta do capital internacional por meio da atuação de organismos multilaterais nas políticas públicas sociais, principalmente por meio de repasses financeiros a organizações sociais. Ainda, segundo Dagnino (2004), tal hegemonia se perpetua de forma sutilmente construída por meio do uso de referências comuns, como parte do que chamou de confluência perversa, no qual o deciframento dos reais interesses torna-se verdadeiramente custoso, em especial para os próprios membros da chamada sociedade civil organizada, que muitas vezes não percebem a dissemelhança de sentidos destes vocábulos, quando empregados a serviço da lógica dominante, por lhes serem tão familiares. Para Dagnino (2004, p. 198), "a disputa política entre projetos políticos distintos assume então o caráter de uma disputa de significados para referências aparentemente comuns: participação, sociedade civil, cidadania, democracia".

Entre os três arranjos, o Vozes é aquele que melhor se enquadra no modelo e discurso

3 Programa de Valorização de Iniciativas Culturais promovido pela Prefeitura de São Paulo que apoia financeiramente grupos e coletivos formados, principalmente por jovens de baixa renda e de regiões da cidade desprovidas de recursos e equipamentos culturais.

4 Projeto da Prefeitura de São Paulo, que tem como objetivo o apoio financeiro a projetos e ações culturais em andamento nos distritos ou bolsões com altos índices de vulnerabilidade social, especialmente nas áreas periféricas do Município 
neoliberal, voltado ao empreendedorismo. Casaqui (2015) explica que os sentidos do neoliberalismo não provêm apenas de um discurso retórico. Eles almejam formatar novas realidades sociais que se estruturam, acima de tudo, no mundo do trabalho. Não é coincidência, portanto, que as premissas de disseminação do modelo neoliberal estejam sempre pautadas em fundamentos alusivos à esfera do trabalho. Nesse discurso, adota-se a perspectiva da individualização, exaltando as concepções como talento, empreendedorismo, profissionalismo e protagonismo.

Outro forte debate que rege a temática da juventude no campo acadêmico mostra como o "discurso da oportunidade" fortalece o estereótipo do jovem periférico associado à violência que, submetido à vulnerabilidade social, necessita ser "resgatado". Nesse ideário, a desigualdade social deixa de ser um problema macroestrutural, para ser uma demanda de solução individual. Para Castro (2005), este sentido foi amplamente disseminado no Brasil via organismos multilaterais - como, neste caso, a Unesco, ao influenciar diretamente a forma como se pensam políticas educacionais no país. Ainda de acordo com esse autor, o produto das ações implementadas pela Unesco-Brasil "é a construção de um problema e a indicação dos principais atores e das vítimas" (CASTRO 2005, p. 4 apud NASCIMENTO, 2014, p. $5^{5}$ ) e se expressaria no trinômio juventude-violência-cidadania.

\section{Território e periferia: algumas reflexões}

Segundo Santos (2000), desde o século 19, o termo território se associa ao papel desempenhado pelo Estado no controle das relações entre as classes sociais e os espaços ocupados. Mas outros sentidos devem ser pensados. Para este autor, o "território é o chão e mais a população, isto é, uma identidade, o fato e o sentimento de pertencer àquilo que nos pertence." (sANTOS, 2000, p. 96). O território é a base do trabalho, da residência, de trocas materiais e espirituais onde a própria vida se desenvolve. Haesbaert (2007) explica que o território nasce historicamente com uma dupla conotação, material e simbólica, porque ao mesmo tempo tem a ver com a dominação jurídico-política da terra e com o medo, especialmente, para aqueles que ficam alijados $\mathrm{da}$ terra ou são impedidos de nela entrar. Território se refere, portanto, tanto ao poder de dominação quanto ao poder em sentido simbólico de apropriação, que se refere às marcas do que é vivido e gera identificação. 
D'Andrea (2013,) explica que o sentimento de ser periférico é uma experiência social urbana baseada na segregação socioespacial. Morar na periferia significa estar distante de áreas mais bem estruturadas da cidade e de onde os habitantes têm maior poder aquisitivo. Essa experiência se expressa ainda na dificuldade de deslocamento no trajeto trabalho-moradia, na busca de serviços oferecidos em bairros com melhor infraestrutura, no acesso as opções de lazer e cultura distribuídas de maneira desigual pela cidade. Esse autor sustenta que o termo periferia mudou de significado ao longo do tempo. Foi primeiro apropriado por intelectuais acadêmicos, a partir dos anos 1960 e passa a ter outro sentido na década de 1990, com o lançamento do álbum Raio X Brasil, do grupo Racionais MC's. Para D'Andrea (2013), foi a partir desse momento que o termo passou a ter um forte componente crítico.

\section{Periferia como lugar de enunciação}

Do ponto de vista discursivo, a cidade pode ser analisada como espaço simbólico e significante (ORLANDI, 2012; ZOPPI-FONTANA, 2003), interpretado pelos sujeitos que se identificam nas representações desses espaços presentes na memória discursiva. São espaços de significação que permitem aos sujeitos se movimentarem em posições discursivas diversas, legitimadas ou silenciadas, assumindo configurações hegemônicas ou de resistência no discurso social (ANGENOT, 2015) que interferem na formação de identidades sociais. Nesse sentido, partimos da análise das denominações dessas iniciativas para compreender como se constitui o discurso desses sujeitos.

Periferia em movimento, Nós, mulheres da Periferia e Vozes são três exemplos de iniciativas jornalísticas que delimitam seu campo específico de atuação abordando as questões presentes em áreas da cidade de São Paulo, que podem ser denominadas genericamente de "periferias". Em que pesem as inúmeras diferenças que podem ser identificadas em cada uma dessas iniciativas e regiões onde surgiram, acreditamos ser necessário refletir sobre os sentidos instaurados no discurso presente nas denominações e no recorte do real que elas produzem. Nesta análise, nos apoiamos nos estudos discursivos na tradição materialista (PÊCHEUX, 2014a; ORLANDI, 2007; ZOPPI-FONTANA, 2003) e na semântica do acontecimento proposta por Guimarães (2017).

Podemos observar que, com exceção do Vozes, as demais iniciativas adotam em seu nome a palavra "periferia". Na perspectiva de Guimarães (2017), os enunciados se produzem numa materialidade histórica do real na qual os sujeitos são afetados pelo simbólico. Desse modo, o sujeito que enuncia assume uma posição no interdiscurso. Ademais, é necessário admitir que o político afeta materialmente 
a linguagem, instaurando a divisão dos sentidos (ORLANDI, 2007; GUIMARÃES, 2017). Desse modo, os nomes das iniciativas jornalísticas demonstram as posições assumidas pelos sujeitos, já afetados por uma divisão de sentidos por eles assumidas na enunciação e na sua formulação discursiva. Na análise de discurso materialista, conforme explica Lagazzi (2011), o sujeito não domina os sentidos, dizendo o que é possível ser dito a partir das posições que o constituem. Reconhece-se que as condições de produção do discurso são determinações históricas não evidentes para o sujeito, mas que o levam a produzir respostas considerando as relações de força presentes na sociedade capitalista.

Ao nomear as iniciativas utilizando a palavra "periferia", os sujeitos rememoram os sentidos postos no discurso científico que divide o espaço geográfico em áreas centrais, onde se situa o comando da produção capitalista e se concentram os espaços reservados para a reprodução da vida social das camadas mais favorecidas da população, e áreas periféricas, que vivem em função das áreas centrais e são reservadas para as camadas desfavorecidas da sociedade. A incidência do discurso geográfico na nomeação dessas iniciativas remete à posição assumida pelos sujeitos numa ordem social desigual e se aproxima dos sentidos que podem ser projetados para "periferia". Este movimento de sentidos visa assim inserir o sujeito numa produção discursiva que se identifica à da periferia. Notemos que "periferia" é enunciada no singular em ambas as iniciativas. De que periferia se trata? Onde ela se situa? Em relação a que centro? Evita-se uma designação ${ }^{6}$ que se estabilize neste discurso, produzindo o efeito de identificação com todos aqueles que se consideram moradores ou leitores de alguma "periferia", que corresponde a uma organização do espaço urbano naturalizada e evidenciada nos discursos dos trabalhadores. "Periferia" torna-se, portanto, um vocábulo que permite ao sujeito identificar-se na sua exclusão em relação às áreas centrais, ao modo de vida que elas representam. Nesse lugar de enunciação, o sujeito adere ao discurso que o coloca no lugar de pertencer à periferia, assumindo-o como parte da sua identidade e como lugar de enunciação, a partir do qual os sentidos são elaborados. Desse modo, o espaço ocupado pelo sujeito condiciona sua existência e se integra à sua identidade.

6 Assim como Guimarães (2017, p. 9), consideramos a nomeação como "funcionamento semântico pelo qual algo recebe um nome" e a designação se refere à "significação de um nome, mas não enquanto algo abstrato. Seria significação enquanto algo próprio das relações de linguagem, mas enquanto uma relação linguística (simbólica) remetida ao real, exposta ao real, ou seja, enquanto uma relação tomada na história." 
Zoppi-Fontana (2018) afirma que as identificações se referem aos processos de produção de sentido e do sujeito, reforçando ao mesmo tempo o imaginário social e abrindo possibilidades de deslocamento de sentidos que geram novos modos de subjetivação. Ocorre, na visão da autora, um processo de interpelação subjetiva e ideológico complexo e contraditório que se materializa nos discursos e nas enunciações dos sujeitos afetados por um saber e um modo de falar sobre si. A constituição de lugares de enunciação para estes sujeitos, nos quais emergem modos de dizer, ocorre na produção histórica de sentidos, que incluem processos de interdição, demandas por reconhecimento e práticas discursivas de resistência. Nessa perspectiva teórica, os lugares de enunciação devem ser pensados como processos de subjetivação articulados às possibilidades históricas de enunciação.

Em Periferia em movimento, o sujeito gramatical é "periferia", apagando-se dessa forma os sujeitos que a colocam em movimento e remetendo para uma coletividade que seria responsável por esta ação. Em Nós, mulheres da periferia, propõe-se uma restrição do sentido. O "nós" são as mulheres, sejam as que produzem as notícias, sejam as leitoras. O espaço geográfico delimitado pela periferia se associa à referência ao gênero, expresso no aposto "mulheres da periferia". São as mulheres da periferia que se dirigem a outras mulheres da periferia, construindo o imaginário de uma identidade das mulheres que habitam este espaço determinado apenas pelo substantivo "periferia", que assinala ainda as particularidades e desigualdades a que estão sujeitas as mulheres moradoras da periferia. Em ambas as iniciativas, os sujeitos estabilizam o sentido para a periferia, lugar de diferenciação na ordem do discurso e na ordem social. Busca-se um universo logicamente estabilizado de sentidos (PÊCHEUX, 2015) para construir um discurso sobre aquilo que denominam periferia, um lugar indeterminado e não particularizado, que se opõe implicitamente ao centro. O discurso dos sujeitos dessas iniciativas visa produzir o efeito de que eles falam a partir do lugar de quem vive na periferia, o que lhes autoriza a discorrer sobre uma realidade conhecida por eles.

A trajetória da formulação de sentidos do Vozes é distinta das anteriores. Em primeiro lugar, o jornal foi intitulado de Vozes da Comunidade da Vila Prudente. Em seguida, o nome foi mudado para Vozes da Vila Prudente e, por fim, apenas Vozes. Nessa trajetória, pode-se perceber que, em vez de estabelecer uma identificação diretamente com o discurso geográfico e explicitar a divisão material que afeta a sociedade e a linguagem a partir desse lugar de enunciação, a designação leva ao sentido de pertencimento a uma área do bairro da Vila Prudente, na Zona Leste de São Paulo. 
Evita-se uma vinculação direta aos sentidos de "periferia". Notemos que, apesar de pertencer a este bairro, há uma diferença em relação a ele que se inscreve no enunciado. Pode-se interpretar que as vozes da comunidade são aquelas das classes desfavorecidas e também para as quais o jornal se dirige, já que o sintagma "comunidade" pode ser parafraseado por "favela". Comunidade pode ainda designar os laços afetivos que envolvem o grupo social presente neste espaço geográfico. A mudança de nome para Vozes da Vila Pudente, ao eliminar o sintagma "comunidade", apaga os sentidos que vinculavam a iniciativa às classes desfavorecidas. Busca-se a identificação em relação ao espaço geográfico circunscrito pelo bairro da Vila Prudente. Por fim, a nomeação Vozes se desvincula de qualquer designação geográfica, afastando-se de suas identificações originais. As vozes expressas no nome do jornal podem ser as de qualquer um, dispersas na sua indeterminação. Nessa trajetória de sentidos, desprende-se do processo de nomeação a identificação de quem são os enunciadores do discurso. Rejeita-se também a identificação e o lugar enunciativo que se associa ao sintagma "periferia", vinculado às classes desfavorecidas.

\section{Periferia e identidade profissional}

A afirmação do vínculo do território com as origens de quem vive nas áreas periféricas da cidade de São Paulo é um fator que permite aos fundadores dessas iniciativas jornalísticas definirem sua identidade profissional ou pessoal, constituindo um discurso que dá sustentação à sua atividade. Ao mesmo tempo que reivindicam tal identidade, demarcam fronteiras discursivas que reforçam seu afastamento em relação ao jornalismo praticado na mídia comercial, característica das áreas centrais. Woodward (2014) explica que a construção da identidade é tanto simbólica quanto social. Tal construção depende ainda da marcação simbólica da diferença em relação a outras identidades, de modo a delimitar um espaço entre "nós" e"eles". Pela marcação simbólica, define-se quem pode ser incluído numa categoria identitária. Admite-se que essas identidades são fluidas e cambiantes, mas é necessário que elas se fixem para que possam se definir no sistema de representação social que as sustenta. Da mesma forma, Hall (2015, p. 11-12) defende que a identidade é "formada e transformada continuamente em relação às formas pelas quais somos representados ou interpelados nos sistemas culturais que nos rodeiam."

A identidade, conforme Orlandi $(2007,2012)$, pode ser considerada como um movimento do sujeito do discurso na história, constituindo-se como processo de identificação de posições do sujeito, interpelado pela ideologia, disponíveis no interdiscurso. Os processos de identificação são instáveis e podem ser 
reconfigurados nos movimentos do sujeito na história. A homogeneidade da identidade e sua estabilidade semântica são um trabalho histórico e simbólico. Haveria assim uma fixação provisória dos processos de interpelação e identificação ideológica dos sujeitos do discurso em determinadas posições e como efeito de relações de dominância e subordinação entre as formações discursivas (ZOPPI-FONTANA, 2003).

Pode-se dizer que a origem nos bairros periféricos da cidade de São Paulo dos integrantes dessas iniciativas é o ponto de partida de uma história profissional que passa pela valorização dessas comunidades e que dará os contornos para a definição de um segmento de atuação com características próprias. Desse modo, Nós, mulheres da periferia reúne jornalistas cofundadoras de bairros da Zona Leste, da Zona Sul e da Zona Norte de São Paulo; o Vozes tem sua origem na Vila Prudente, na Zona Leste, e o Periferia em Movimento, no Grajaú, na Zona Sul. Observa-se que a divisão territorial da cidade de São Paulo não só nos seus elementos geográficos, mas também culturais e simbólicos, são fatores de identificação que aglutinam sentidos que são adotados por esses jornalistas para conferirem um rumo a suas experiências profissionais.

Ser da periferia permite assim filiar-se aos sentidos que os determinam. Tais posições assumidas por eles reforçam os sentidos atribuídos aos bairros periféricos, marcados pela pobreza, pela exclusão social e pela violência, ao mesmo tempo que buscam instaurar sentidos positivos para a área geográfica e seus moradores. Dessa forma, o sujeito da periferia se constitui no imbricamento dos estigmas que os definem no discurso hegemônico que vigora nas áreas centrais acerca das periferias e pela valorização que se busca fazer nos veículos de comunicação dessas áreas periféricas, dotadas de uma cultura específica e pouco conhecida. Como exemplo, podemos observar em (1) que a memória da violência é retomada como parte da história do sujeito, algo que se repete ("a outra vez") e afeta a muitos ("depois eu fui ver no Facebook que muitas casas tinham sido invadidas"). Em (2), a periferia é "o lugar de construção da identidade", definido pela geografia, pela distância em relação ao centro, mas também como lugares de "maioria negra", de "maioria pobre", "de maior índice de vulnerabilidade social" e "maior violação de direitos".

A periferia que aglutina os sentidos da desigualdade social e da violência é também "lugar de resistência". Vale, portanto, aproximá-la da memória da resistência dos quilombos, que compõe um outro modo de significação em relação à senzala, lugar onde moravam os escravos, como o faz o sujeito em (3). A senzala é representada no "quartinho 
de empregada", cômodo característico em residências de classe média e alta. A periferia é lugar de violência, resultado da exclusão social, e resistência: "Eles jogam a gente nesses lugares pra gente morrer pra gente se matar e tentar fazer com que a gente se mate o tempo todo, mas nesse lugar também surge toda a resistência, esse é um lugar de resistência, e é dessa resistência que a gente tem que falar, né?". Esse lugar de resistência tem de ser elaborado na prática jornalística, por meio de fontes da periferia (4) e de "histórias da favela" (5), ou seja, "histórias que reforcem o poder da favela financeiramente, cultural, é local, geográfico, ah, mas que essas histórias inspirem outras pessoas, contem casos de vitória que alguém da favela teve".

Lugares de enunciação são assim formados em oposição aos existentes na mídia dominante e em relação à representação proposta por esses veículos, como observa o sujeito em (3): "Então também é uma forma de desmistificar o jornalismo" e "então é também desmistificar o que é notícia, pra que ele entenda como que esse mecanismo tá estruturado, né?". A mesma preocupação aparece na fala dos sujeitos em (4): "A gente tenta fazer o contrário, daquilo que a pessoa disse a gente dá mais importância para a gente ir atrás das outras fontes, então esta que é sempre a voz da mulher da periferia no caso, o que ela tem a dizer."
A outra vez eu tava, tinha acabado de chegar do trabalho, tava cansado, e aí eu tava dormindo, era muito cedo, dia de jogo quarta-feira, nove e meia da noite eu tava dormindo, quando eu acordo tem um policial no meu quarto com a arma apontada pra mim, eu nem mexi e nem falei nada, só observei, aí até que meu pai subiu atrás do policial e aí o policial falou pra eu levantar com a mão na cabeça e eu, ainda tava meio perdido, e falei 'que que tá acontecendo, gente?' até que depois eu fui ver no Facebook que muitas casas tinha sido invadidas. (Entrevistado, Vozes)

É... acho que é... territo... é... territorializado né que aí eu acho que não é só so lance geográfico quando a gente fala da distância, mas é o lugar de construção de identidade. Esses territórios, são territórios de maioria jovem, são territórios de maioria negra, são territórios de maioria pobre, são territórios de maior índice de vulnerabilidade social, né, ou seja, com maior indi... com maior violação de direitos, então, cê... é... você vai sobrepondo e, são nesses territórios que a gente constrói uma identidade, ou várias identidades né, e que a gente constrói essas formas de fazer, então, é...(Entrevistado Periferia em Movimento).

Então também é uma forma de desmistificar o jornalismo, porque quando a gente pergunta pro moleque na escola, o que que é notícia no seu bairro? Ele... sabe, quando a gente pergunta isso, ele vai falar "ah, é notícia..." ele vai lembrar da grande... só da grande mídia, "ah, teve um assassinato aqui, teve um assalto, teve não sei o que..." [...] a décima opinião: "não, mas teve uma vez que fizeram uma peça de teatro" sabe, então é também desmistificar o que que é notícia, pra que ele entenda como que 
esse mecanismo tá estruturado, né, não é... então o que que acontece nesse bairro, só tem coisa ruim acontecendo aqui? Cadê a potência? Né, cadê o que é construído aqui? Cadê o... sabe, as soluções, que são elaboradas aqui? Porque são só... porque a gente foi jogado nesse lugar pra morrer sabe?! A gente criou formas de sobreviver, né, então... as periferias, elas são quilombos né, é... as pessoas dizem que são senzala né, tem aquela frase "quando a senzala aprende a ler, a casa grande surta". Não é senzala né, a senzala tá aqui no quartinho de empregada, isso é senzala, a periferia é quilombo né, eles... eles jogam a gente nesses lugares pra gente morrer, pra gente se matar e tenta fazer com que a gente se mate o tempo todo né, mas nesse lugar também surge toda a resistência, esse é um lugar de resistência, e é dessa resistência que a gente tem que falar,né.? (Entrevistado, Periferia em Movimento).

Eu acho que tanto no Mural quanto no Nós a ideia de que fonte da periferia é a mais importante. Então a gente muda um pouco o foco, quando a gente vai fazer uma matéria no grande veículo ele vai fazer tudo, tudo, tudo e vai pegar uma "raspazinha" para comprovar que ouviu minimamente alguém. A gente tenta fazer o contrário, daquilo que a pessoa disse a gente dá mais importância para a gente ir atrás das outras fontes, então esta que é sempre a voz da mulher da periferia no caso, o que ela tem a dizer (Entrevistada, Nós, mulheres da periferia)

Até porque a gente, eu particularmente penso que a gente produz jornalismo, jornalismo local, comunitário, em especial comunitário, mas a gente já passou por outras vertentes, assim, de jornalismo, a gente já produziu contação de histórias através do jornalismo, a gente já produziu jornalismo investigativo, acho que é uma variável dentro do Vozes, mas em geral, nosso foco é contar histórias da favela. Então, histórias que reforcem o poder da favela financeiramente, cultural, é local, geográfico, ah, mas que essas histórias inspirem outras pessoas, contem casos de vitória que alguém da favela teve. (Entrevistado, Vozes).

Assumir a posição de um sujeito da periferia ou de seu porta-voz é uma construção feita a partir da trajetória profissional marcada pelo conhecimento de realidades simbólicas distintas que definem a cultura universitária e o mercado de trabalho, moldado pelas práticas jornalísticas dominantes e distantes de qualquer identidade ou vínculo com as periferias. A formação em jornalismo confere-lhes o repertório para atuação no mercado de trabalho nos moldes tradicionais. Esses sujeitos passam a ser afetados pelo discurso acadêmico que lhes permite refletir sobre sua condição e sua origem social. Em (6), o conhecimento adquirido na faculdade de jornalismo é instrumentalizado em benefício da "favela", ameaçada de desapropriação. Contar as histórias desses moradores, sobretudo consolidando sentidos de pertencimento ao lugar, torna-se uma ferramenta de luta social para o sujeito que estudava jornalismo e buscava "construir um diálogo com o governo do Estado". Em (7), o conflito em relação ao discurso dominante, que considera a periferia lugar de violência, ocorre na 
universidade: "a gente ia falar com algum professor sobre a pesquisa e ele falava: 'Mas vocês vão entrar lá com câmera?', 'vocês vão gravar lá dentro?", mas lá dentro era onde a gente morava, então... como assim né?! "A orientadora da área de TV não conseguia entender a proposta de trabalho de conclusão de curso sobre a periferia e a visão dela é totalmente diferente daquela que a gente queria mostrar".

Mas é também na universidade que os estudantes encontram referencial para sustentar a experiência de configuração da identidade e do lugar de enunciação da periferia, por meio do auxílio dos professores de Antropologia ("era a única professora negra que tinha na Universidade, era professora de Antropologia, ela dava aula na... foi uma das primeiras professoras da Zumbi do Palmares também, então ela tinha uma outra... ela tinha uma visão mais ampla sobre o que que a gente tava falando") e de rádio ("Tinha um professor também que não era do audiovisual, mas ele era do rádio e ele tinha alguns estudos, que ele já tinha feito sobre jornalismo alternativo.")

0 Vozes surgiu em 2013, meados de 2013, com o objetivo na época de tentar, na época, construir um diálogo com o governo do Estado, mostrar pro governo do Estado que aqui na favela da Vila Prudente existem pessoas com uma enorme referência da favela que não poderiam ser removidas por conta de uma obra, ah, tão desorganizada na época. E aí, enfim, conversei com alguns líderes locais na época e falei 'meu, to estudando jornalismo e tal, já tenho um pouquinho de conhecimento, acho que existe alguma forma de eu contribuir para que esse diálogo aconteça, né' e aí todos eles apoiaram e eu comecei a contar histórias de moradores da favela dentro de um blog. Todas as histórias que eu criava eu mandava pra subprefeitura, pra alguns e-mails que eu tenho do governo e enfim, saia divulgando. E daí, calhou dessa força, desse movimento, ser criado, ser criado não, ser levado pra equipe que estava organizando essas obras do metrô aqui na região. E aí sim abriu-se um diálogo, não com o governo, mas com 0 metrô, que começou a ouvir mais os moradores, em especial um líder local. (Entrevistado, Vozes)

Os professores não entendiam o que a gente queria falar, assim... é... a gente escolheu uma orientadora que... foi uma péssima escolha, porque como a gente decidiu fazer um documentário, a gente pensou: vamos escolher alguém que trabalha com algo relacionado a isso! Ela trabalhava na TV... ela era professora de telejornalismo, trabalhava na TV Record e a gente acabou optando por ela ser a nossa orientadora, só que a visão dela é totalmente diferente daquela que a gente queria mostrar entendeu?! É... no fim das contas a gente tinha uma orientadora paralela, que era uma professora de Antropologia, que não era nossa professora, mas ela era profe... a gente descobriu no Campus ela... essa... ela acabou sendo também .. nossa... parte da nossa banca e era a única professora negra que tinha na Universidade, era professora de Antropologia, ela dava aula na... foi uma das primeiras professoras da Zumbi do Palmares também, então ela tinha uma outra... ela tinha uma visão mais ampla sobre o que que a gente 
tava falando né, não sobre a técnica em si, mas ela tinha sobre o objeto de estudo né, 0 que que a gente tava... sobre o que que a gente queria abordar, então foi fundamental, e tinha um professor também que não era do audiovisual, mas ele era do rádio e ele tinha alguns estudos, que ele já tinha feito sobre jornalismo alternativo, por conta do... por conta do interesse dele por rádio.. né ele já tinha pesquisado sobre rádios comunitárias e tudo mais que ele trouxe um pouco também, porque ele não era nosso orientador mas ele trouxe, ele auxiliou um pouco nessa questão de entender a comunicação comunitária, alternativa, que também era algo que a gente tava pesquisando né, mas não foi tão tranquilo não, porque era isso, a gente ia falar com algum professor sobre a pesquisa e ele falava: "Mas vocês vão entrar lá com câmera?" "vocês vão gravar lá dentro?", mas lá dentro era onde a gente morava, então... como assim né?! (Entrevistado Periferia em movimento)

A busca por uma colocação no mercado de trabalho, as dificuldades e o distanciamento das questões da periferia que definem a origem dos integrantes dessas iniciativas são fatos a serem destacados como definidores de sua trajetória em direção à formação de um discurso que assume a identidade da periferia. Para estes profissionais, a inserção no mercado de trabalho nos modelos tradicionais de jornalismo requer do sujeito a assunção de posições conflituosas em relação ao discurso de defesa de práticas sociais emancipatórias ${ }^{7}$. O sujeito deve transitar do seu espaço de origem para outros, em que as ordens sociais e simbólicas são distintas e conflitantes. Instaura-se uma contradição que se define pelo choque entre as realidades simbólicas percebidas pelo sujeito. Inserir-se neste mercado de trabalho, de certa forma, significa distanciar-se das questões que marcaram a origem de cada um. Altera-se a trajetória profissional desses jornalistas que se veem distantes do modelo convencional de jornalismo e passam a buscar alternativas para uma atuação profissional que combine práticas jornalísticas e uma certa militância social em prol das comunidades que vivem nestas áreas. Ser da periferia confere a seu discurso autoridade para falar de uma realidade suficientemente conhecida por eles.

A difícil inserção no mercado de trabalho leva o sujeito em (8) a buscar atividades nas quais possa exercer seu conhecimento: revisão de texto, assessoria de imprensa, redes sociais, comunicação interna e projeto do blog Mural da Folha, no qual se inicia o coletivo Nós, mulheres da periferia, configurando um outro domínio para atividade profissional, 
uma "alternativa para fazer jornalismo nas horas vagas", ainda que esta não seja sua fonte de renda. Em (9), o sujeito identifica os conflitos que ocorrem nas experiências com o jornalismo tradicional: a realidade da periferia é diferente daquela retratada na "mídia hegemônica", aproximando-se muito mais das narrativas descritas nos raps ("nosso primeiro veículo de comunicação periférico, de fato"). Ainda assim, a realidade do Grajaú era desconhecida e estereotipada: "ninguém sabia... ninguém sabia nem onde a gente ficava entendeu?! Então, tinha inclusive nisso né, essa questão da representatividade, a gente não se vê, né? e quando a gente se vê era pra falar de tragédia, né, era pra falar de violência, era pra falar de... de desmoronamento."

Após uma experiência de trabalho na TV Globo, o sujeito prefere abrir mão do emprego, porque não correspondia à proposta original que o motivou: "não era realmente aquilo que contaram pra gente lá atrás, então, continuou quem queria. Eu preferi não continuar porque são poucas as pautas que o programa tem agora sobre periferia, sobre juventude, acho que essas que tiveram foram as que eu e o roteirista indicamos", afirma o entrevistado em (10).

Bom eu me formei em jornalismo em 2008, e eu fiquei um tempinho sem trabaIhar depois eu entrei numa empresa para trabalhar com revisão de texto porque eu estava fazendo Letras ainda, eu concluí o curso de jornalismo e fazia letras também. Aí eu concluí o jornalismo procurei trabaIho na área, mas era muito difícil, recém-formada, não era estágio nem experiência para trabalhar, todas as especificações que eles pedem e você não tem. Eu fui para a área de revisão, eu fiquei na empresa de revisão por dois anos e depois eu saí para trabalhar numa ONG com comunicação aí eu fazia assessoria de imprensa, redes sociais, comunicação interna eu era referência da comunicação toda da ONG porque não tinha uma equipe de comunicação. A equipe era eu e a designer que fazia as artes gráficas. Eu fiquei lá por um ano e depois eu saí e entrei numa agência de assessoria de imprensa. Eu fiquei três anos com essa agência e saí depois para entrar no Sesc que eu já estou há 7 meses. Paralelamente a isso, desde 2011, eu entrei no projeto blog Mural da Folha que era na época que eu estava trabalhando na revisão, então foi uma coisa que eu vi como uma alternativa para fazer jornalismo nas horas vagas que era o que eu queria fazer. Eu estava desmotivada na área de textos e tal. Em 2014 depois dessa experiência do mural a gente fundou o projeto coletivo Nós, Mulheres da Periferia e também está desde 2014. Então eu tô nesses dois projetos independentes que não são minha fonte de renda desde 2011 para cá. (Entrevistada, Nós, mulheres da periferia)

Eu acho que são esses conflitos, que eu falei, esses conflitos que a gente vivencia na faculdade, esses conflitos que a gente vivencia... acho que nessas experiências aí de trabalho, nesse mundo do jornalismo aí, é... esses conflitos nos... né... no fazer jornalístico, por que que a gente tá falando disso sabe?! Enquanto... aí depois você tem que voltar pra casa, só pra dormir 
praticamente... por que era isso né, saia de casa seis e meia da manhã e voltava, chegava meia noite, então você acaba não vivendo tudo aquilo, e a gente não se via né, a gente não se via, é diferente até do Capão Redondo, do Jardim Ângela, que ficaram estigmatizados por conta da violência, é... e só se falava disso, quando se falava do Capão Redondo, Jardim Ângela, e mesmo Capão Redondo ainda assim tinha uma representatividade maior por conta dos Racionais, né?! Por que a gente tem que colocar o Rap aí, porque a gente pode não... podia não ter TV, rádio, Site, mas a gente tinha o Rap, né, o nosso... nosso primeiro veículo de comunicação periférico, de fato, é o Rap, né?! Então, Racionais, Facção Central, Trilha Sonora do Gueto, Realidade Cruel e tudo mais, e quando os Racionais falava do Capão Redondo, cê tinha um contraponto que a...que a mídia hegemônica falava, só que quando você falava do Grajaú, ninguém sabia... ninguém sabia nem onde a gente ficava entendeu?! Então, tinha inclusive nisso né, essa questão da representatividade, a gente não se vê, né? e quando a gente se vê era pra falar de tragédia, né, era pra falar de violência, era pra falar de... de desmoronamento. (Entrevistado, Periferia em Movimento)

Eu acredito que seria continuar como pesquisador havendo essa possibilidade de ser roteirista porque eu trabalhava muito próximo de um roteirista em especial, e esse roteirista quando eu me desliguei, eu me desliguei e não falei pra ninguém porque estava a dois dias de começar o programa na TV, e aí ele veio me perguntar porque eu não havia ido naqueles dois dias e aí eu falei: "não, eu pedi pra sair, meu contrato finalizou, só não queria falar antes do início' o programa ia começar na terça-feira, se não me engano, e no domingo ele também pediu demissão, então, aí enfim, não era realmente aquilo que contaram pra gente lá atrás, então, continuou quem queria. Eu preferi não continuar porque são poucas pautas que o programa tem agora sobre periferia, sobre juventude, acho que essas que tiveram foram as que eu e 0 roteirista indicamos. (Entrevistado, Vozes).

Assumir a identidade da periferia e distanciar-se do mercado tradicional do jornalismo implica lançar-se a uma rotina intensificada de trabalho, na qual a iniciativa se torna uma das atividades, muitas vezes secundária e sem garantir a sobrevivência material dos que nela trabalham. É possível dizer que os sujeitos entrevistados têm dificuldade de aderir às formações discursivas ${ }^{8}$ e às práticas de trabalho presentes no modelo hegemônico de jornalismo. No entanto, é necessário buscar uma inserção no mercado da comunicação, ainda que seja seguindo os ditames da lógica do empreendedorismo social (CASAQUI, 2015). Para tanto, vale procurar formações específicas, participar de grupos que fomentem tais práticas, vistas como possibilidade de

8 Pêcheux (2014a, p. 160) define formação discursiva como "aquilo que numa formação ideológica dada, isto é, a partir de uma posição dada numa conjuntura dada, determinada pelo estado da luta de classes, determina o que pode e deve ser dito." 0 autor afirma ainda que "toda formação discursiva dissimula, pela transparência do sentido que nela se constitui, sua dependência com respeito ao 'todo complexo com dominante' das formações discursivas, intrincado no complexo das formações ideológicas" (PÊCHEUX, 2014a, p. 162). 
manter a sustentabilidade das iniciativas. Neste aspecto, podemos observar a tensão que se estabelece no interior da formações discursiva que constituem o ideário que justifica as práticas jornalísticas na periferia. De acordo com Pêcheux (2014b), uma formação discursiva não é um espaço estrutural fechado, pois é invadida por elementos que vêm de outro lugar, ou seja, de outras formações discursivas que lhes fornecem evidências. Da mesma forma, Courtine (2009) afirma que as formações discursivas não são blocos homogêneos separadas de outras formações por fronteiras rígidas. Ao contrário, há deslocamentos nessas fronteiras e pode-se observar a alteridade que constitui a formação discursiva. Nesse sentido, pelo que podemos compreender no movimento de sentidos que se estabelece no discurso dos entrevistados, o discurso do empreendedorismo social é admitido pelos sujeitos, isto é, ele faz parte da formação discursiva a qual se filiam, que combina, portanto, de um lado um discurso de afirmação da identidade da periferia e de outro um que valoriza as práticas de mercado. Movimentam-se assim estes sujeitos entre posições diversas disponíveis no interdiscurso, interpelados por uma ideologia de resistência e, ao mesmo tempo, de submissão ao mercado, tal como se propõe no discurso neoliberal, como podemos observar abaixo. Apagam-se assim as contradições que podem ser apontadas na formulação do discurso dos entrevistados.
Em (11), o sujeito percebe a precariedade da sua experiência ("é um desgaste muito grande", "porque a gente depende infelizmente de fazer outras coisas para se manter"). A saída é ser um negócio, mas um "negócio social". O adjetivo social permite que o sujeito se distancie de práticas voltadas para obtenção de lucro simplesmente. O sujeito deposita suas esperanças no futuro ("longo prazo"), marcado pela incerteza: "se eventualmente a gente conseguir que isso seja nossa fonte de trabalho, que a gente consiga se manter individualmente, cada uma também com isso eu acho que vai ser positivo". Ser uma franquia social, modalidade de negócio, é também motivo de euforia para o sujeito em (12), que vê esta possibilidade como solução para a manutenção do projeto, porque a "franquia social quem banca são as empresas". Nesse modelo, a metodologia desenvolvida para o negócio pode ser usada em outras iniciativas. Ter sido selecionado para participar de uma iniciativa que visava "acelerar" projetos sociais é também visto positivamente pelo sujeito em (13): "a gente tinha um... um capital mínimo ali, que a gente conseguia dedicar tempo, a gente tinha consultoria do... da rede ali, do Hub também pra... pra entender isso que a gente tava fazendo".

A gente só não é remunerada mesmo. É um desgaste muito grande, inclusive, por isso que a gente tenta a longo prazo, a gente quer um dia que ele seja sustentável para a 
gente poder ter mais tempo para fazer isso. [...[ A gente está com essa meta de ter um site que consiga minimamente a gente ter, não lucro né, porque a gente se vê como um negócio social, que a gente tenta conceitos de jornalismo de causas, mas que a gente consiga pelo menos manter os custos que a gente tem da própria produção. Se eventualmente a gente conseguir que isso seja nossa fonte de trabalho, que a gente consiga se manter individualmente, cada uma também com isso eu acho que vai ser positivo. Mas pelo menos por hora a gente está pensando em manter o próprio projeto.. (Entrevistada, Nós, mulheres da periferia)

A gente foi selecionado pra ser uma franquia social, o que isso é: a partir do ano a gente vai ter mais trabalhos ligados a cultura, esporte, ah...[...] quando surgiu 0 empreendedorismo social eu falei "pô, é, seria como uma empresa, só que a pessoa visa mais o social e tal", uma franquia social é: existe um empreendimento social, um negócio social e esse negócio social, a metodologia dele vai ser franquiada pra outros lugares [...] diferente do processo de franquia comum. A franquia social quem banca são empresas que têm o destino social, mas, o local que vai receber ele entra só com recursos humanos, então, ele forma a equipe, prepara o local pra fazer o trabalho social, que é o que a gente tá fazendo agora.[...], a gente tem dois apoiadores que é o Carlos Wizard, dono da Wizard e outro parceiro nosso que mora nos Estados Unidos, brasileiro que mora nos Estados Unidos, é, serão os dois apoiadores. (Entrevistado, Vozes)

É e aí eles criam um programa lá com... pra formação de empreendedores sociais criativos, né?, que foi bem numa época que teve o boom do VAl, então a gente...[...], e aí eles criam um programa voltado pra essa galera da cultura nas periféricas né, que são... que tem... que são da área criativa, que tem impacto social na visão deles e tal, a gente se inscreve e a gente acabou passando cinco meses num processo pra entender como que a gente vive do que a gente faz né, então uma formação de negócios mesmo, mas é... voltado pra essas especificidades desses coletivos né. Foi muito louco assim, foi impor... foi importantíssimo, e aí no final, é... desses vinte e tanto projetos, três foram selecionados pra um projeto de incubação pelo Hub que seria pra acelerar esse processo e aí a gente acabou sendo um dos... um dos selecionados né, então foram de maio a dezembro de dois mil e treze a gente tinha um... um capital mínimo ali, que agente conseguia dedicar tempo, a gente tinha consultoria do... da rede ali, do Hub também pra... pra entender isso que a gente tava fazendo, (Entrevistada, Periferia em movimento)

\section{Considerações finais}

A constituição de uma identidade dos jornalistas da periferia é ponto central para a organização de sua formulação discursiva. Ser da periferia os autoriza a produzir um discurso legitimado e distinto em relação à mídia hegemônica, que buscar marcar uma diferença no modo de compreender a sociabilidade e as questões vividas pelos moradores da periferia. Sobressaem-se assim as experiências e histórias dos sujeitos, que rememoram e reafirmam os sentidos postos na memória social para periferia, como espaço delimitado pela pobreza e pela violência, procurando também 
instaurar sentidos de afirmação da diferença cultural que igualmente marca as comunidades que vivem nessas áreas da cidade de São Paulo. A narrativa estabelecida feita pelos sujeitos traz a memória da precariedade social como definidora de uma história de vida, que precisa ser considerada na relação com as práticas profissionais. Vincular-se a uma comunidade da periferia é compreender as injunções sociais e simbólicas a que essa população está submetida e que são constitutivas de sua história. A sustentação desse discurso dá suporte para o estabelecimento de uma experiência profissional que se aproxima das comunidades.

Chama a atenção o fato de que a insatisfação com o modo como o regime de produção jornalística tradicional se manifesta. Instaura-se um conflito com essa ordem de produção simbólica, o que leva os jornalistas entrevistados a repensar seu território de origem social de modo a transformá-lo no ponto de partida também para sua sobrevivência como jornalistas. A criação das iniciativas não parece comportar dificuldade. A experiência profissional, aliada ao conhecimento da realidade da periferia e à proximidade com os moradores dessas regiões, são os ativos que se destacam no projeto iniciado na reunião de profissionais que compartilham a mesma origem ou que estudaram juntos nas mesmas instituições de ensino. A tarefa, que exige os maiores esforços, é tornar viáveis tais iniciativas para que elas possam servir de fonte de recursos para a sobrevivência pessoal e como atividade de trabalho que não seja apenas definida pelos ditames comerciais.

A viabilidade econômica dessas iniciativas é frágil e depende da motivação pessoal dos integrantes dos grupos e da busca de outras atividades remuneradas capazes de responder à manutenção da vida pessoal. Tais dificuldades, aliadas ao financiamento rarefeito do Estado e de fundações, os leva a aderir ao ideário e ao discurso do empreendedorismo social. Na visão dos entrevistados, esta é uma forma de garantir a sobrevivência dos projetos. Assim, a viabilidade desses arranjos só se torna possível no discurso de seus integrantes se seguir o modelo ditado pelas práticas de mercado. Empreender é também visto como uma possibilidade para evitar o acúmulo de atividades num contexto definido pela precariedade. O sujeito é convocado a ser autônomo, a tornar-se empreendedor, inserindo-se de outro modo na ordem socioeconômica que o precariza e o aliena de suas origens sociais.

\section{Referências}

ANGENOT, Marc. $\mathbf{O}$ discurso social e as retóricas da incompreensão: consensos e conflitos na arte de (não-persuadir). São Carlos: Edufscar, 2015. 
ANTUNES, Ricardo. 0 privilégio da servidão: o novo proletariado de serviços na era digital. São Paulo: Boitempo, 2018

BAUER Martin; GASKELL, George. Pesquisa qualitativa com texto, imagem e som: um manual prático. 6. ed. Petrópolis: Vozes, 2007.

CASAQUI, Vander. A construção do papel do empreendedor social: mundos possíveis, discurso e o espírito do capitalismo.

Galaxia, São Paulo, n. 29, p. 44-56, jun. 2015. Disponível em: <http://www.scielo.br/ scielo.php?script=sci_arttext\&pid=S1982$25532015000100044 \& \operatorname{lng}=e n \& n r m=i s o>$. Acesso em: 31 out. 2019.

CASTRO, João Paulo Macedo e. UNESCO: Educando os jovens cidadãos e capturando redes de interesses; uma pedagogia da democracia no Brasil. Rio de Janeiro: UFRJ/ PPGAS, 2005.

COURTINE, Jean-Jacques. Análise do discurso político: o discurso comunista endereçado aos cristãos. São Carlos: Edufscar, 2009.

D’ANDREA, Tiarajú Pablo. A formação dos sujeitos periféricos: cultura e política na periferia de São Paulo. 2013. Tese (Doutorado)Universidade de São Paulo, São Paulo, 2013.

DAGNINO, Evelina. Confluência perversa, deslocamento de sentido, crise discursiva. In: GRIMSON, Alejandro. (Org.) La cultura en las crisis latinoamericanas. Buenos Aires: Clacso, 2004.

\section{GUIMARÃES, Eduardo. Semântica do}

acontecimento: um estudo enunciativo da designação. 4. ed. Campinas: Pontes, 2017.

GRAMSCI, Antonio. Cadernos do cárcere. Rio de Janeiro: Civilização Brasileira, 2007. (v. 3).
HALL, Stuart. A identidade cultural na pós-modernidade. 12. ed. Rio de Janeiro: Lamparina, 2015.

HAESBAERT, Rogério. Território e multiterritorialidade: um debate.

GEOgraphia, Niterói, Ano IX, v. 9, n. 17, p. 19-46, 2007. https://doi.org/10.22409/ GEOgraphia2007.v9i17.a13531

HANDCOCK, Mark; GILE, Krista. On the concept of snowball sampling. Ithaca, NY: Cornell University Library, 2011. Disponível em:<https://arxiv.org/abs/1108.0301v1>. Acesso em 30 out. 2019.

LAGAZZI, Suzy. A equivocidade na circulação do conhecimento científico. Linguagem em (Dis)curso, v. 11, n. 3, p. p. 497-514, fev. 2012. Disponível em: <http://www. portaldeperiodicos.unisul.br/index.php/ Linguagem_Discurso/article/view/818>. Acesso em: 12 jul. 2017.

MONTAÑO, Carlos. Terceiro setor e questão social: crítica ao padrão emergente de intervenção social. São Paulo: Cortez, 2002.

ORLANDI, Eni. Interpretação: autoria, leitura e efeitos do trabalho simbólico. Campinas: Pontes, 2007.

ORLANDI, Eni. Discurso e texto: formulação e circulação dos sentidos. 4. ed. Campinas: Pontes, 2012.

ORLANDI, Eni. Análise de discurso: princípios e procecedimentos. 8. ed. Campinas:

Pontes, 2015.

PÊCHEUX, Michel. Semântica e discurso: uma crítica à afimação do óbvio. 5. ed. Campinas: Edunicamp, 2014a. 
PÊCHEUX, Michel. A análise de discurso: três épocas. In: GADET, Françoise; HAK, Tony (Org.). Por uma análise automática do discurso: uma introdução à obra de Michel Pêcheux. 3. ed. Campinas: Editora da Unicamp, 2014b. p. 311-319.

PÊCHEUX, Michel. O discurso: estrutura ou acontecimento? 7. ed. Pontes: Campinas, 2015. PEDRINA, B.; MOREIRA, J.; PENINA, M.; OLIVEIRA, S.; SILVIA, P. Tendências/Debates: Nós, mulheres da periferia. Folha de S. Paulo, 2012, p. 2

SAMPIERI, Roberto Hernández; COLLADO, Carlos Fernández; LUCIO, Maria del Pilar Baptista. Metodologia de pesquisa. São Paulo: McGraw Hill, 2006.

SANTOS, Milton. Por uma outra globalização: do pensamento único à consciência universal. Rio de Janeiro: Record, 2000.

WOODWARD, Kathryn. Identidade e diferença: uma introdução teórica e conceitual.
In: SILVA, Tomás Tadeu; WOODWARD, Kathryn; HALL, Stuart (Org.). Identidade e diferença: a perspectiva dos estudos culturais. 15. ed. Petrópolis: Vozes, 2014. p. 7-72.

ZOPPI-FONTANA, Mónica. Identidades (i)nformais: contradição, processos de designação e subjetivação na diferença. Organon, Porto Alegre, v. 17, n. 35, p. 245-282, 2003. Disponível em: <https://seer.ufrgs.br/ organon/article/view/30027/18623>. Acesso em: 30 out. 2019.

ZOPPI-FONTANA, Mónica. 'Lugar de fala': enunciação, subjetivação, resistência. Revista Conexão Letras, Porto Alegre, v. 12, n. 18, jan. 2018, p. 63-71. Disponível em: <https://seer. ufrgs.br/conexaoletras/article/view/79457>. Acesso em: 13 out. 2019.

YAZBEK, Maria Carmelita. Serviço Social, Questão Social e Políticas Sociais em tempos de degradação do trabalho humano, sob o domínio do capital financeiro. Serviço Social em Revista, v. 21, n.1, p. 183-194, 2018.

\section{Informações sobre 0 artigo}

Resultado de projeto de pesquisa: 0 artigo é um dos desdobramentos da pesquisa As relações de comunicação e as condições de produção no trabalho de jornalistas em arranjos econômicos alternativos às corporações de mídia, feita pelo Centro de Pesquisa em Comunicação e Trabalho, do qual os autores fazem parte.

Fontes de financiamento: Projeto com apoio financeiro da Fundação de Apoio à Pesquisa no Estado de São Paulo, processo n $201606992-3$

Considerações éticas: A pesquisa foi aprovada pelo Comitê de Ética da EACH-USP (5390).

Declaração de conflito de interesses: Não se aplica.

Apresentação anterior: 0 artigo foi originalmente apresentado no Congresso da Associação Brasileira de Pesquisadores em Jornalismo (SBPJor) de 2018, e revisto com as adequações dos resultados das discussões sobre 0 trabalho.

Agradecimentos/Contribuições adicionais: Agradecemos a todos os membros pesquisadores e associados do Centro de Pesquisa em Comunicação e Trabalho (CPCT-ECA/USP). 


\section{Peripherie: a place for identity in journalists' speech}

\section{Periferia: un lugar para la identidade en el discurso de los periodistas}

\begin{abstract}
Periferia em movimento, Nós, mulheres da periferia e Vozes are examples of journalistic initiatives that delimit their field of action in areas of the city of São Paulo called "peripheries". The purpose of this article is to understand the discourse process initiated by these alternative economic arrangements to the media corporations and manifested in interviews with representatives of these initiatives. The analysis, which follows theoretical and methodological principles of materialist Discourse Analysis, indicates that the constitution of an identity of a journalist from the periphery is decisive for its discursive formulation and for legitimizing a distinct discourse in relation to the hegemonic media.
\end{abstract}

\section{Keywords:}

Journalism. Periphery. Discourse Analysis.

\section{Résumen}

Periferia em movimiento, Nós, mulheres da periferia e Vozes, son ejemplos de iniciativas periodísticas que delimitan su campo de acción en áreas de la ciudad de São Paulo llamadas "periferias". El propósito de este artículo es comprender el proceso de discurso iniciado por estos arreglos económicos alternativos para las corporaciones de medios y manifestado en entrevistas con representantes de estas iniciativas. El análisis, que sigue los principios teóricos y metodológicos del análisis del discurso materialista, indica que la constitución de la identidad de un periodista de la periferia es decisiva para su formulación discursiva y para legitimar un discurso distinto en relación con los medios hegemónicos.

\section{Palabras clave:}

Periodismo. Periferia. Análisis del discurso.

\section{Cláudia Nonato}

Doutora em Ciências da Comunicação pelo Programa de Pós-graduação em Ciências da Comunicação da Escola de Comunicação e Artes da Universidade de São Paulo. Pesquisadora do Centro de Pesquisa em Comunicação e Trabalho.

Universidade de São Paulo, São Paulo, Brasil

E-mail: claudia.nonato@uol.com.br ORCID: https://orcid.org/0000-0002-5447-9761

\section{Fernando Felício Pachi Filho}

Doutor em Ciências da Comunicação pelo Programa de Pós-graduação em Ciências da Comunicação da Escola de Comunicação e Artes da Universidade de São Paulo. Professor da Faculdade de Tecnologia Termomecânica (FTT) e do Instituto de Ciências Sociais e Comunicação da Universidade Paulista (UNIP).

Faculdade de Tecnologia Termomecânica, São Bernardo do Campo, São Paulo, Brasil Universidade Paulista, São Paulo, São Paulo, Brasil E-mail: ffpachi@yahoo.com.br ORCID: https://orcid.org/0000-0002-1667-4937

\section{Camila Acosta Camargo}

Doutoranda em Ciências da Comunicação pelo Programa de Pós-graduação em Ciências da Comunicação da Escola de Comunicação e Artes da Universidade de São Paulo. Professora do curso de Relações Públicas no FIAM-FAAM Centro Universitário.

Universidade de São Paulo, São Paulo, Brasil FIAM-FAAM Centro Universitário, São Paulo, São Paulo, Brasil

E-mail: camila.acosta.camargo@usp.br ORCID: https://orcid.org/0000-0002-1188-5014

\section{Contribuição dos autores:}

Concepção e desenho do estudo: Fernando Felício Pachi Filho; Cláudia Nonato; Camila Acosta Camargo.

Aquisição, análise ou interpretação dos dados:

Fernando Felício Pachi Filho; Cláudia Nonato.

Redação do manuscrito: Fernando Felício Pachi Filho;

Cláudia Nonato; Camila Acosta Camargo.

Revisão crítica do conteúdo intelectual: Fernando Felício Pachi Filho; Cláudia Nonato; Camila Acosta Camargo. 